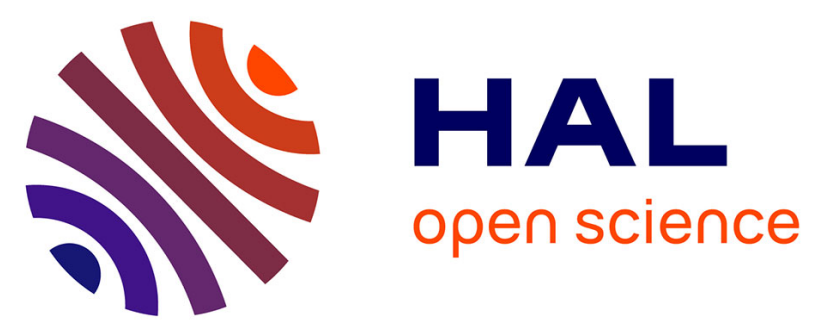

\title{
Improved Mixed Oxide Fuel Calculations with the Evaluated Nuclear Data Library JEFF-3.2
}

\author{
Gilles Noguere, Bernard David, Patrick Blaise, Olivier Bouland, Luiz C. Leal, \\ Pierre Leconte, Olivier Litaize, Yannick Pénéliau, Benedicte Roque, Alain \\ Santamarina, et al.
}

\section{To cite this version:}

Gilles Noguere, Bernard David, Patrick Blaise, Olivier Bouland, Luiz C. Leal, et al.. Improved Mixed Oxide Fuel Calculations with the Evaluated Nuclear Data Library JEFF-3.2. Nuclear Science and Engineering, 2017, 182 (2), pp.135-150. 10.13182/NSE15-9 . cea-02386210

\section{HAL Id: cea-02386210 https://hal-cea.archives-ouvertes.fr/cea-02386210}

Submitted on 29 Nov 2019

HAL is a multi-disciplinary open access archive for the deposit and dissemination of scientific research documents, whether they are published or not. The documents may come from teaching and research institutions in France or abroad, or from public or private research centers.
L'archive ouverte pluridisciplinaire HAL, est destinée au dépôt et à la diffusion de documents scientifiques de niveau recherche, publiés ou non, émanant des établissements d'enseignement et de recherche français ou étrangers, des laboratoires publics ou privés. 


\title{
Improved MOX fuel calculations with the Evaluated Nuclear Data Library JEFF-3.2.
}

\author{
G. Noguere ${ }^{\mathrm{a}}$, D. Bernard ${ }^{\mathrm{a}}$, P. Blaise ${ }^{\mathrm{a}}$, O. Bouland $^{\mathrm{a}}$, L. Leal $^{\mathrm{b}}$, \\ P. Leconte ${ }^{\text {a }}$, O. Litaize ${ }^{a}$, Y. Peneliau a ${ }^{a}$ B. Roque ${ }^{\text {a }}$, \\ A. Santamarina ${ }^{\mathrm{a}}$, J-F. Vidal ${ }^{\mathrm{a}}$, \\ ${ }^{a}$ CEA, DEN, DER Cadarache, F-13108 Saint Paul les Durance, France \\ ${ }^{\mathrm{b}}$ Oak Ridge National Laboratory, P.O. Box 2008, Oak Ridge, Tennessee 37831, \\ USA.
}

\begin{abstract}
An overestimation of the $k_{\text {eff }}$ values for MOX fuels was identified with MonteCarlo (TRIPOLI4) and deterministic (APOLLO2) calculations based on the Evaluated Nuclear Data Library JEFF. The overestimation becomes sizeable with the $\mathrm{Pu}$-ageing, reaching a reactivity change of $\Delta \rho \simeq+700 \mathrm{pcm}$ for integral measurements carried out with MOX fuel containing a large amount of Americium. This bias was observed on various critical configurations performed in the zero power reactor EOLE of the CEA Cadarache, France. The present work focuses on the improvements achieved with the new ${ }^{239} \mathrm{Pu}$ and ${ }^{241} \mathrm{Am}$ Evaluated Nuclear Data Files available in the latest version of the JEFF library (JEFF-3.2). The Resolved Resonance Range of the plutonium evaluation was re-evaluated at ORNL (Oak Ridge National Laboratory) with the SAMMY code in collaboration with the CEA Cadarache. The resonance parameters of the Americium evaluation were obtained with the REFIT code in collaboration with the research institutes IRMM (Institute for Reference Materials and Measurements, Geel, Belgium) and Irfu (Institut de recherche sur les lois fondamentales de l'Univers, Saclay, France).
\end{abstract}

\section{Introduction}

Numerous integral experiments on MOX fuel configurations were carried out in the zero power reactor EOLE of the CEA Cadarache, France. The interpretation of the experimental results is routinely performed with the deterministic code APOLLO2 [1] and Monte-Carlo code TRIPOLI4 [2] developed at the CEA Saclay, France. The data application library used by both codes for neutron transport calculations is based on the nuclear data available in 
the Joint Evaluated Fission and Fusion library (JEFF). The integral results provide valuable nuclear data trends for the continuous improvement of JEFF under the non-regression principle. Results given in this paper are illustrated with $k_{\text {eff }}$ values obtained for the MH1.2, FUBILA, MISTRAL-2, MISTRAL-3 and MISTRAL-4 programs where the residual reactivity are measured through critical fuel loading or/and critical soluble boron concentration.

The nuclear data of interest for MOX fuel calculations were significantly improved since the release of the JEF-2.2 library in 1992. The present work focuses only on the description of the resolved resonance range of the neutron cross sections for which an incremental method was adopted for modifying and correcting resonance parameters of the plutonium $\left({ }^{239} \mathrm{Pu},{ }^{240} \mathrm{Pu},{ }^{241} \mathrm{Pu}\right)$ and americium $\left({ }^{241} \mathrm{Am}\right)$ isotopes. The method is described in Ref. [3]. Despite the evaluation works performed on these isotopes for the JEFF-3.1.1 library, we still observe systematic overestimation of the experimental $k_{\text {eff }}$ by results of calculations that increases with the $\mathrm{Pu}$-ageing, which defines the ${ }^{241} \mathrm{Am}$ build up from ${ }^{241} \mathrm{Pu}$ beta decay with time. For the reference configuration of the MISTRAL-4 experiments, the bias on the calculation-to-experimental ratios reaches $+735(8)$ pcm. Such biases were recently reduced with the latest version of the JEFF library, namely JEFF-3.2. The improvements are discussed in the present document.

The second section addresses the context of the present study. A review of the evaluation activities performed on the Plutonium and Americium isotopes is presented in the third section. The experimental programs selected for the "benchmarking" of the new Evaluated Nuclear Data Files are briefly described in section 4. Results expressed in terms of reactivity effects are discussed in section 5 .

\section{Context}

The resolved resonance range of the Plutonium and Americium isotopes of interest for MOX fuel calculations was elaborated in three steps. Explanations are reminded in Ref. [3]. New evaluated nuclear data files for ${ }^{240} \mathrm{Pu}$ and ${ }^{241} \mathrm{Pu}$ were proposed for the release of JEFF-3.0, while corrections for ${ }^{241} \mathrm{Am}$ and ${ }^{239} \mathrm{Pu}$ were included in JEFF-3.1 and JEFF-3.1.1 respectively. Figure 1 compares the evaluated and experimental neutron cross sections for the first resonances of each isotope. 

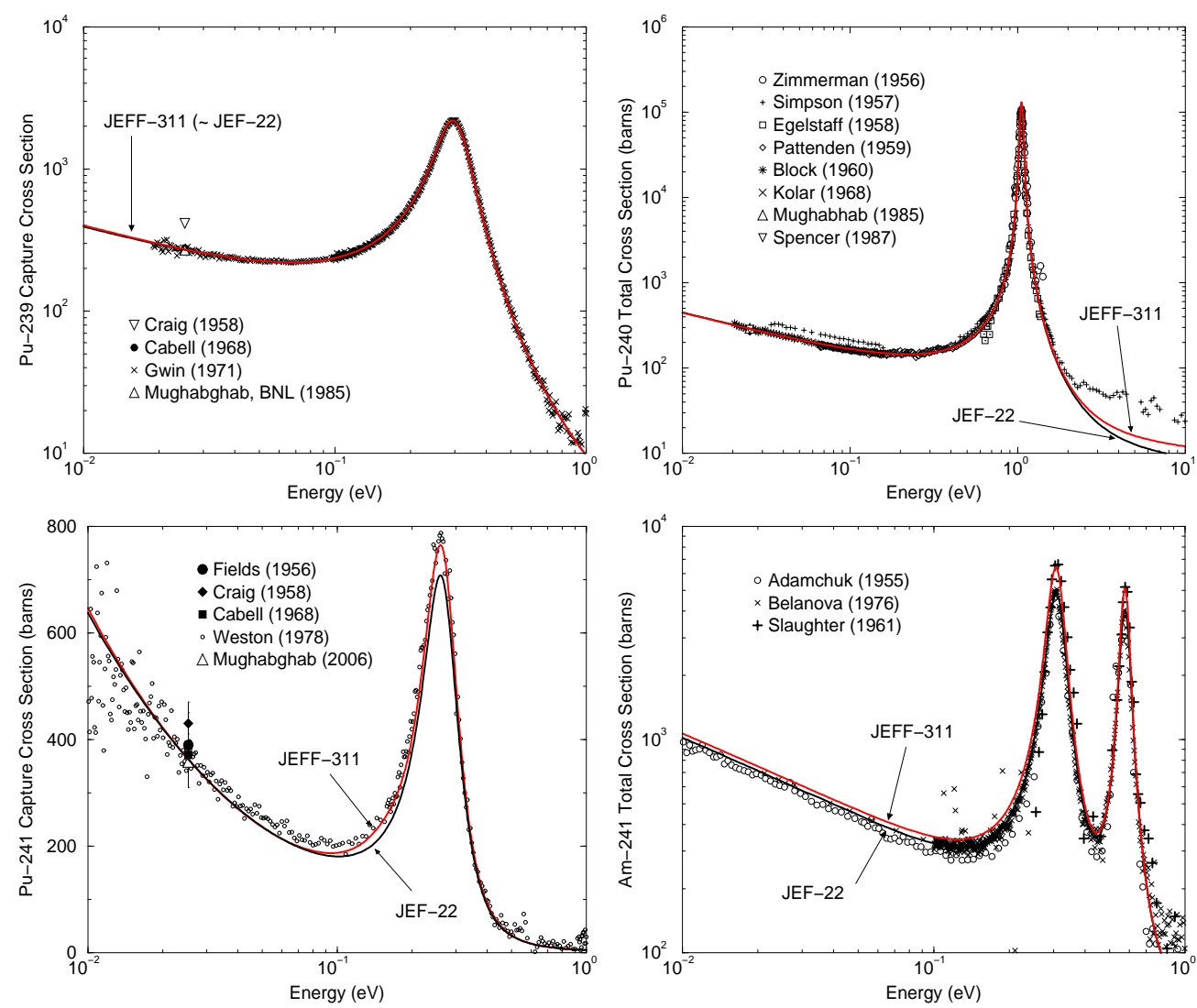

Fig. 1. ${ }^{239} \mathrm{Pu},{ }^{240} \mathrm{Pu},{ }^{241} \mathrm{Pu}$ and ${ }^{241} \mathrm{Am}$ neutron cross sections reconstructed with the resonance parameters of the JEFF libraries. The experimental data are taken from the EXFOR data base [4].

\subsection{From JEF-2.2 to JEFF-3.0}

Inconsistent descriptions of the low energy capture and fission cross sections of several actinides compiled in the JEF-2.2 library were identified with an Integral Data Assimilation procedure (called RDN) on a large variety of integral data. The results exhibited the need of new resonance analysis of ${ }^{240} \mathrm{Pu}$ and ${ }^{241} \mathrm{Pu}$. The evaluation work was performed with the SAMMY code [5] in collaboration with ORNL.

For ${ }^{241} \mathrm{Pu}$, the SAMMY analysis focuses on the first s-wave resonance at 0.26 $\mathrm{eV}$ [6]. The new resonance parameters evaluated with the Reich-Moore approximation of the R-Matrix theory allowed a correct prediction of the ${ }^{242} \mathrm{Pu}$ and ${ }^{243} \mathrm{Am}$ build-up as a result of an increasing of the capture resonance integral $(+6.5 \%)$ and of the partial radiation width $\Gamma_{\gamma}$ from $32.6 \mathrm{meV}$ (in JEF-2.2) to $34.6 \mathrm{meV}$ (in JEFF-3.1.1). Comparisons with data retrieved from the experimental data base EXFOR are shown in Fig. 1.

The nuclear system ${ }^{240} \mathrm{Pu}+\mathrm{n}$ is characterized by a broad resonance at $1.06 \mathrm{eV}$ 

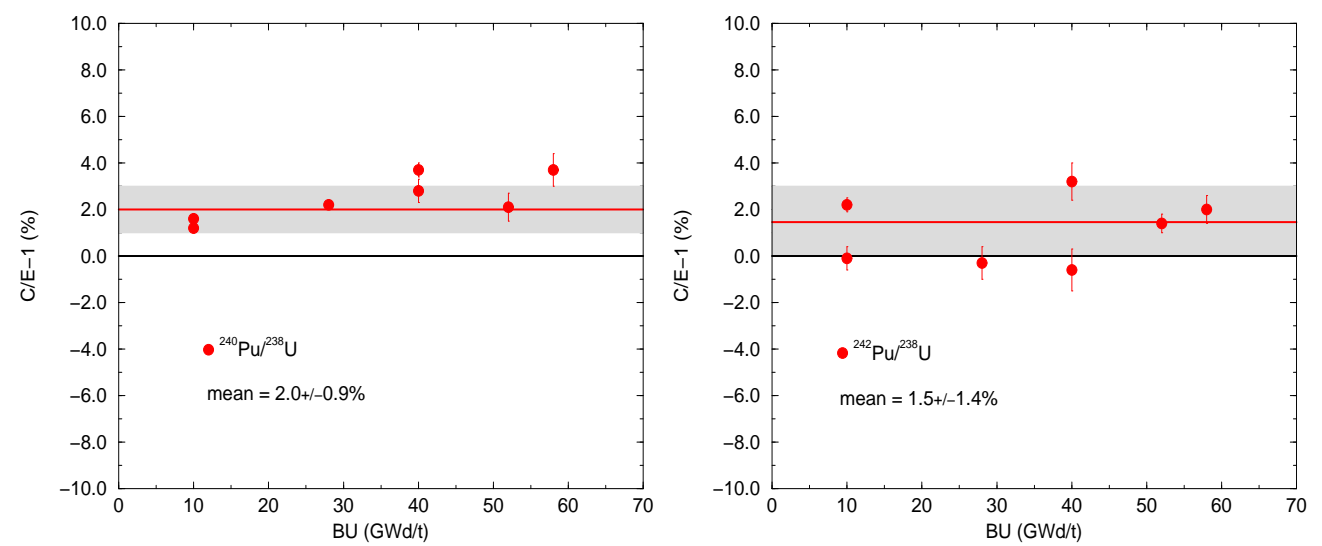

Fig. 2. MOX fuel inventory calculations performed with the DARWIN package by using the JEFF-3.1.1 library [9].

with a cross-section peak that is as high as 20 kbarns. Small changes on the parameters that describe this resonance may have a significant impact on MOX calculations because it represents $95 \%$ of the ${ }^{240} \mathrm{Pu}$ capture rate and almost $30 \%$ of the total capture rate in MOX fuel. The resonance parameters compiled in JEFF-3.1.1 were established from two sets of transmission data measured at the ORELA facility with a thin and thick samples at nitrogen temperature $(T=77 \mathrm{~K})$ [7]. Detailed explanations on the resonance analysis performed up to $5.7 \mathrm{keV}$ are given in Ref. [8]. The main issue was the assessment of the effective temperature $\left(T_{\text {eff }}=109.6 \mathrm{~K}\right)$ to account for the Doppler broadening.

Performances of the evaluated nuclear data files for ${ }^{240} \mathrm{Pu}$ and ${ }^{241} \mathrm{Pu}$ were investigated with experimental results obtained from irradiated fuel samples. Calculations performed with the DARWIN package are presented in Ref. [9]. The prediction of the ${ }^{240} \mathrm{Pu}$ and ${ }^{242} \mathrm{Pu}$ build-up are summarized in Fig. 2.

\subsection{From JEFF-3.0 to JEFF-3.1}

The impact of the first four s-wave resonances of ${ }^{241} \mathrm{Am}$ at $0.3 \mathrm{eV}, 0.6 \mathrm{eV}$, $1.3 \mathrm{eV}$ and $1.9 \mathrm{eV}$ on average integral trend was investigated prior the release of JEFF-3.1. The main motivations for revising the lower part of the ${ }^{241} \mathrm{Am}$ neutron cross sections were based on integral trends that suggested an increase of the thermal capture cross section and of the epithermal resonance integral [10]. The evaluation work was performed with the SAMMY code by using the total cross sections measured by Belanova [11], Slaughter [12] and Derrien [13] with the transmission technique. Figure 3 shows the differences between the ${ }^{241} \mathrm{Am}(\mathrm{n}, \gamma)$ cross section of the JEFF-3.0 and JEFF-3.1.1 (=JEFF-3.1) libraries.

This evaluation work led to TRIPOLI4 calculations in better agreement with 


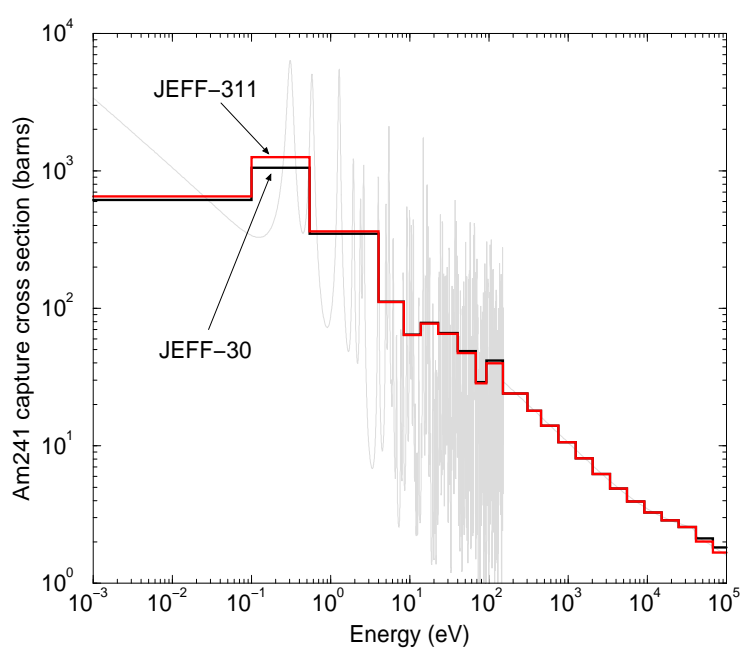

Fig. 3. Comparison of the ${ }^{241} \mathrm{Am}$ broad-group average capture cross section calculated with the JEFF-3.0 and JEFF-3.1.1 library.

Table 1

Average integral trends $\langle C / E-1\rangle$ obtained on the ${ }^{241} \mathrm{Am}(\mathrm{n}, \gamma)$ reactions from the interpretation of the pile-oscillation experiment OSMOSE [14] carried out at the MINERVE facility (CEA Cadarache, France). The calculations were performed with the TRIPOLI code by using the JEFF-3.1.1 and ENDF/B-VII.0 libraries.

\begin{tabular}{cccc}
\hline MINERVE & Exp. & \multicolumn{2}{c}{ Evaluated Nuclear Data Libraries } \\
\cline { 3 - 4 } configurations & unc. & ENDF/B-VII.0 & JEFF-3.1.1 \\
\hline R1UO2 (UOX lattice) & $\pm 2.8 \%$ & $-14.5 \%$ & $-3.8 \%$ \\
R1MOX (MOX lattice) & $\pm 2.4 \%$ & $-12.6 \%$ & $-4.2 \%$ \\
\hline
\end{tabular}

reactivity worth measurements carried out at the MINERVE facility of the CEA Cadarache in the frame of the OSMOSE program [14]. Results are summarized in Table 1. However, calculations based on JEFF-3.1.1 were not able to fully explain differences observed on older integral results carried out in the MELUSINE reactor of the CEA Grenoble (experimental programs ICARE-S, ICARE-R and SHERWOOD) [15], as well as the systematic overestimation of the critical $k_{\text {eff }}$ of $100 \%$ MOX cores of the EOLE facility of CEA Cadarache. The origin of these long standing problems is clarified in section 3.2.

\subsection{From JEFF-3.1 to JEFF-3.1.1}

Evaluation work on ${ }^{239} \mathrm{Pu}$ was focused on the prompt neutron multiplicity and on the $\alpha$ ratio (Fig. 4). The $\alpha$ ratio of ${ }^{239} \mathrm{Pu}$, meaning the ratio of the neutroninduced capture cross-section to the neutron-induced fission cross-section, was investigated in the thermal energy range via Reactivity Temperature Coefficient (RTC) analysis performed with the APOLLO2 code on the MISTRAL-2 
Table 2

Total RTC error (in $\mathrm{pcm} /{ }^{\circ} \mathrm{C}$ ) deduced from the MISTRAL experiments. The calculations were performed with the APOLLO code by using the JEF-2.2 and JEFF3.1.1 libraries [16,17].

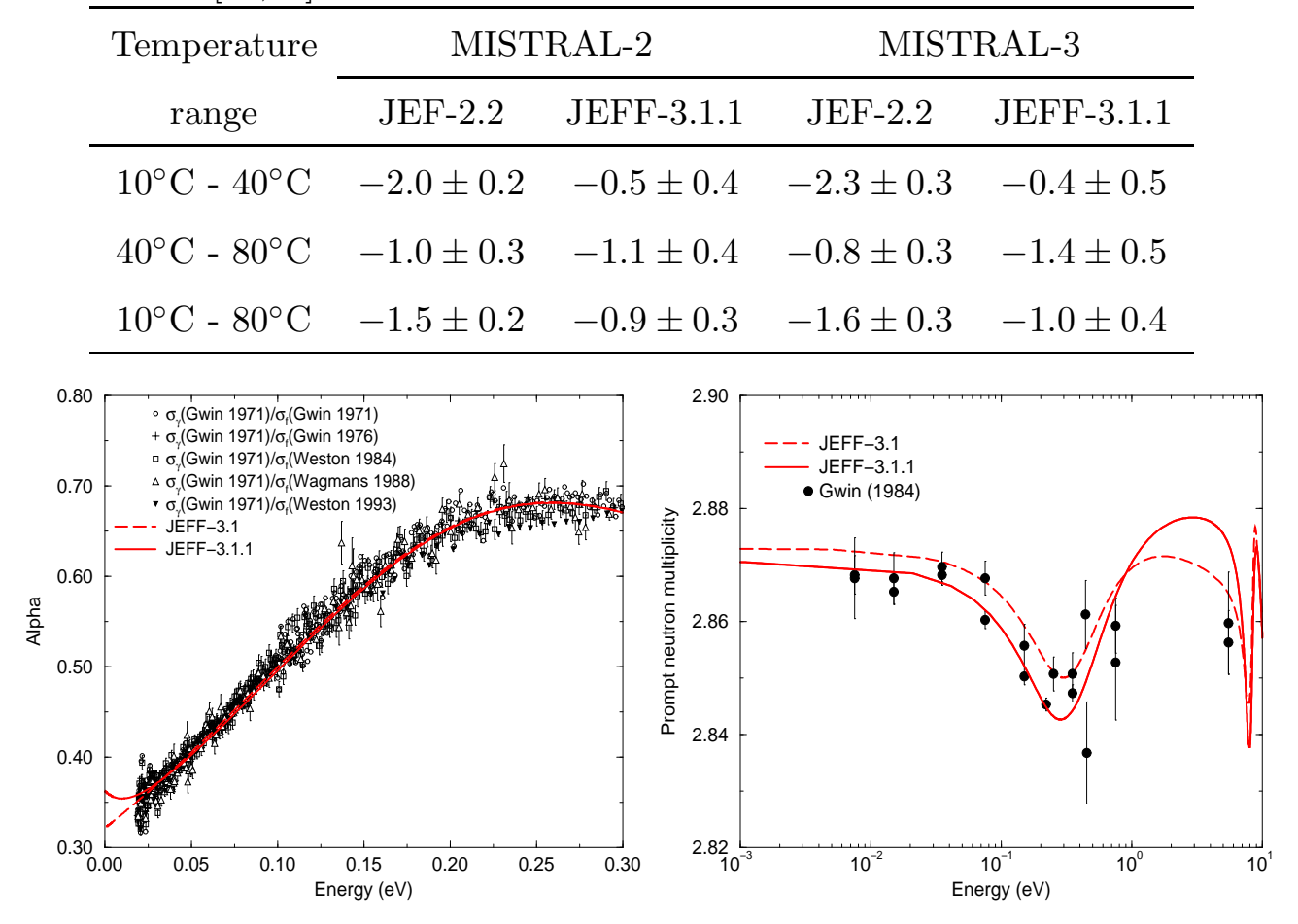

Fig. 4. $\alpha$ ratio (left hand plot) and prompt neutron multiplicity (right hand plot) of ${ }^{239} \mathrm{Pu}$ reconstructed with the JEFF-3.1 and JEFF-3.1.1 libraries. The theoretical curves are compared with EXFOR data.

and MISTRAL-3 experiments carried out in the EOLE facility [16,17]. The interpretation of the experimental results demonstrated that part of the negative bias reported in Table 2 for the low-temperature range (below $80^{\circ} \mathrm{C}$ ) was linked to the thermal spectrum shift effect, which dependents on the thermal shapes of the capture and fission cross-sections of ${ }^{239} \mathrm{Pu}$.

Improved RTC calculations were achieved on the temperature range $\left[10^{\circ} \mathrm{C}\right.$ $80^{\circ} \mathrm{C}$ ] by adding a bound state with a negative energy $(\mathrm{E}=-0.02 \mathrm{eV})$ close to the binding energy. The parameters were optimized to modify the energy dependence of the $\alpha$ ratio below the thermal energy of $25.3 \mathrm{meV}$. Such a modification led to an increase of the thermal capture cross section of 2.1 barns and a decrease of the thermal fission cross section of 0.6 barns.

The ${ }^{239} \mathrm{Pu}$ evaluation was also improved with a new modelisation of the prompt neutron multiplicity up to $20 \mathrm{eV}$. The performances were demonstrated via ICSBEP benchmarks. As shown by the extensive work of Van Der Mark [18] performed over 368 Plutonium Solutions in Thermal spectrum (PST), the average value of the $C / E-1$ results is $+203 \mathrm{pcm}$ for JEFF-3.1.1, compared to $+462 \mathrm{pcm}$ for ENDF/B-VII.1 and +633 pcm for JENDL-4.0. 


\section{Plutonium and Americium Evaluated Nuclear Data Files}

New investigations were conducted on the resolved resonance range of the ${ }^{239} \mathrm{Pu}$ and ${ }^{241} \mathrm{Am}$ isotopes with the aim to explain the systematic overestimation of the MOX reactivity at zero power and room temperature. The differences between the calculations and the experimental results range from few tens to several hundred of pcm on many MOX fuel configurations carried out in the EOLE facility.

The evaluation activities performed on each isotope is described in sections 3.1 and 3.2. The resulting thermal quantities and values for the resonance integrals are reported in Table 3.

\subsection{New description of the ${ }^{239} \mathrm{Pu}$ resolved resonance range}

The update of the ${ }^{239} \mathrm{Pu}$ resolved resonance range was a necessity because of the obsolete data format chosen to store the numerous parameters. In the eighties and early nineties Derrien and others performed an evaluation in a collaborative work including CEA and ORNL. At that time, due to computer limitations for data storage and processing decision was made to split the resonance region in three parts, namely, $\left[10^{-5} \mathrm{eV}-1 \mathrm{keV}\right],[1 \mathrm{keV}-2 \mathrm{keV}]$, and $[2 \mathrm{keV}-2.5 \mathrm{keV}]$. Some additional issues with the evaluation arise from the use of three distinct sets of resonance parameters. The cross-sections calculated at the energy boundary of two consecutive disjoint resonance parameter sets could be different leading to discontinuity. An artificial background cross section was also needed to correct the fission cross section in the second energy range $[1 \mathrm{keV}-2 \mathrm{keV}]$. Another concern relates to data uncertainty assessment using resonance parameter covariance. For data uncertainty analysis the use of a single resonance parameter set covering the entire energy region would be preferable since the disjoint set of resonance parameters do not permit the determination of a fully uncertainty correlation in the entire energy region.

A collaborative effort between the Oak Ridge National Laboratory (ORNL) and the CEA of Cadarache was initiated under the auspice of the US Department of Energy and the Nuclear Energy Agency (NEA) to address issues pertinent to the performance of the ${ }^{239} \mathrm{Pu}$ cross-sections in benchmark calculations. A new resolved resonance analysis was performed in the frame of the WPEC subgroup SG-34 of the Nuclear Energy Agency. Results and discussions are reported in the final report of the working group [20]. The main effort related to the determination of resonance parameters up to $2.5 \mathrm{keV}$ was performed with the SAMMY code at ORNL [21]. The lower energy range of the neutron cross sections was finalized in collaboration with the CEA Cadarache 
Table 3. Thermal quantities, resonance integrals and equivalent $\mathrm{K} 1$ calculated at $293.6 \mathrm{~K}$ with the NJOY code. Results are compared with the data compiled in the Atlas of Neutron Resonance of Mughaghab [19].

\begin{tabular}{llcccccc}
\hline Isotope & & $\nu_{t}$ & $\sigma_{f}$ & $\sigma_{\gamma}$ & $I_{f}$ & $I_{\gamma}$ & $\mathrm{K} 1$ \\
\hline${ }^{239} \mathrm{Pu}$ & Atlas & $2.879 \pm 0.006$ & $748.1 \pm 2.0$ & $269.3 \pm 2.9$ & $303 \pm 10$ & $180 \pm 20$ & \\
& JEFF-311 & 2.875 & 746.9 & 272.7 & 303.6 & 181.5 & 1155.4 \\
& JEFF-32 & 2.875 & 747.2 & 270.1 & 308.8 & 180.1 & 1161.5 \\
\hline${ }^{241} \mathrm{Am}$ & Atlas & & $3.2 \pm 0.1$ & $587 \pm 12$ & $14.4 \pm 1.0$ & $1425 \pm 100$ & \\
& JEFF-311 & 3.239 & 3.2 & 647.0 & 17.3 & 1526.4 & \\
& JEFF-32 & 3.102 & 3.2 & 747.8 & 15.2 & 1826.1 & \\
\hline
\end{tabular}




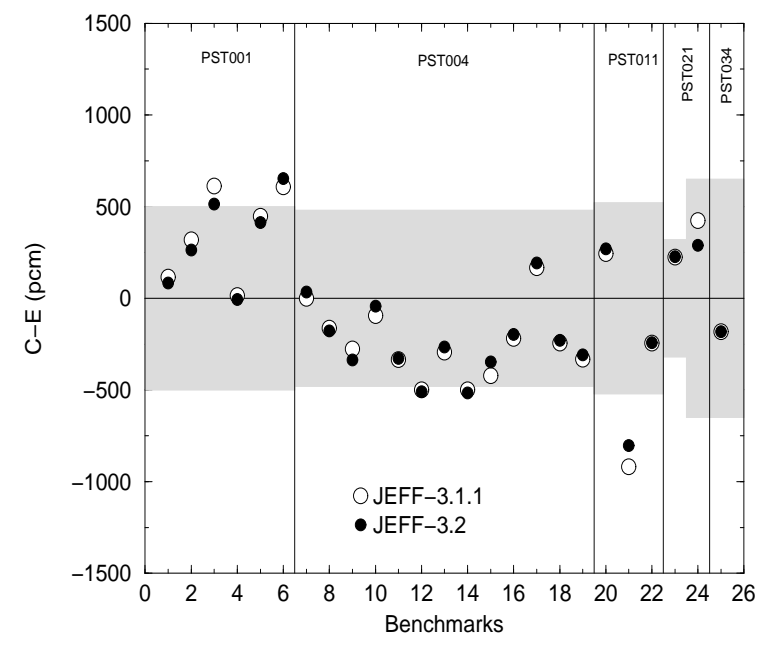

Fig. 5. Comparison of the (C-E) results obtained with JEFF-3.1.1 and JEFF-3.2 for a selected set of thermal solutions of plutonium (PST) $[22,23]$.

in order to account for constraints on the thermal shape of the $\alpha$ ratio (see section 2.3) in conjunction with the fluctuations of the prompt neutron multiplicity $\bar{\nu}_{p}(E)$ established for JEFF-3.1.1. The fitting of the ${ }^{239} \mathrm{Pu}$ nuclear data was continuously monitored during the evaluation procedure with a selected set of ICSBEP benchmarks. This step was crucial to conserve the good performances of the JEFF library on PST benchmarks (Fig. 5).

Thermal quantities and values for the resonance integral are reported in Table 3. An overall good agreement is obtained with the values compiled in Ref. [19]. The main issue is related to the difference between the total neutron multiplicity $\bar{\nu}_{t}=2.8745$ and the value of $2.8836 \pm 0.0047$ recommended by the "standard" expert group of the AIEA. Although the difference (-0.0091) remains within the reasonable limit of two standard deviation, a deeper investigation could reveals compensation effects with the Prompt Fission Neutron Spectrum (PFNS). Few lessons can be drawn from results reported in Ref. [24]. The major conclusion is that calculations of PST benchmarks with softer PFNS of different origins lead to a systematic increase of the $k_{\text {eff }}$ values ranging from $50 \mathrm{pcm}$ to $800 \mathrm{pcm}$. These trends are not compatible with an increase of the neutron multiplicity in the thermal energy range. Complementary benchmarking works are under progress in the frame of the WPEC subgroup SG-40 ( CIELO pilot project) with the aim to clarify these oposite results.

\subsection{Improved description of the ${ }^{241}$ Am capture cross section}

A new resonance analysis of the nuclear system ${ }^{241} \mathrm{Am}+\mathrm{n}$ was performed using recent transmission and capture data measured at the GELINA facility of 
the Institute for Reference Materials and Measurements (IRMM, Belgium). The resonance parameters reported by Lampoudis [25] suggest to increase by $20 \%$ the capture resonance integral. A similar conclusion is obtained with the parameters compiled in JEFF-3.2 [26]. The thermal quantities and resonance integral are compared in Table 3.

Several integral experiments have been designed to measure the neutron capture cross-sections of heavy nuclides involved in fission reactor design calculations. For the nuclear system ${ }^{241} \mathrm{Am}+\mathrm{n}$, we focused our benchmarking activities on the experimental programs carried out in the MELUSINE facility of the CEA Grenoble and in the MINERVE and EOLE facilities of the CEA Cadarache.

Post Irradiated Experiments carried out in the MELUSINE reactor from 1986 to 1988, namely ICARE-S, ICARE-R and SHERWOD, were recently reanalyzed with the APOLLO code [15]. The programs ICARE-S and ICARE-R were dedicated to investigate the neutronic properties of Light Water Reactors with high conversion ratio. They are characterized by a neutron spectrum covering the epithermal energy range. The core configuration of the SHERWOOD program was representative to standard PWR conditions. The combination of these three experiments allows to cover a wide energy range from thermal to few tens of eV. Each experiment consisted in irradiating one or two experimental pins composed of isotopically enriched samples of actinides. Integral trends on the capture cross section can be deduced from the isotopic analyses before and after the irradiation period.

Additional information on the ${ }^{241} \mathrm{Am}$ capture cross section was also deduced from the OSMOSE program carried out in the MINERVE facility with the oscillation technique. Four experimental results were obtained with two ${ }^{241} \mathrm{Am}$ samples oscillated in UOX (R1UO2) and MOX (R1MOX) core configurations [14]. The measured reactivity worth is nearly proportional to the effective capture cross section of ${ }^{241} \mathrm{Am}$.

Complementary results were obtained from the measurements of the $\mathrm{Pu}$ ageing which is obtained from the following difference:

$$
\Delta(\delta t)=k_{\mathrm{eff}}\left(t_{0}+\delta t\right)-k_{\mathrm{eff}}\left(t_{0}\right)
$$

Two experimental results were deduced from the reference configurations of the MISTRAL3 program (1998 and 1999) and FUBILA program (2005 and 2006) carried out in the EOLE facility. A third one was obtained from the reactivity worth of a ${ }^{241} \mathrm{Pu}$ sample oscillated in the MINERVE facility in 2006 and 2009. The strong underprediction of the MINERVE results $(-10.6 \%)$ are significantly improved $(-1.8 \%)$ by using the JEFF-3.2 library. For the EOLE results, the agreement between the experiments and the calculations remains 
Table 4

Integral trends for ${ }^{241} \mathrm{Am}$ deduced from experimental programs carried out in the MELUSINE, MINERVE and EOLE facilities [14,15].

\begin{tabular}{|c|c|c|c|c|c|}
\hline \multirow{2}{*}{$\begin{array}{l}\text { Experimental } \\
\text { facilities }\end{array}$} & \multirow{2}{*}{$\begin{array}{l}\text { Experimental } \\
\text { programs }\end{array}$} & \multirow{2}{*}{$\begin{array}{l}\text { Physical } \\
\text { quantities }\end{array}$} & \multirow{2}{*}{$\begin{array}{l}\text { Exp. } \\
\text { unc. }\end{array}$} & \multicolumn{2}{|c|}{ JEFF libraries } \\
\hline & & & & JEFF-311 & JEFF-32 \\
\hline \multirow[t]{3}{*}{ MELUSINE } & ICARE-R & $(\mathrm{n}, \gamma)$ & $\pm 4.8 \%$ & $-21.4 \%$ & $-9.0 \%$ \\
\hline & ICARE-S & $(\mathrm{n}, \gamma)$ & $\pm 2.7 \%$ & $-15.2 \%$ & $-4.0 \%$ \\
\hline & SHERWOOD & $(\mathrm{n}, \gamma)$ & $\pm 2.1 \%$ & $-16.5 \%$ & $-3.0 \%$ \\
\hline \multirow[t]{3}{*}{ MINERVE } & OSMOSE (R1U02) & $(\mathrm{n}, \gamma)$ & $\pm 2.8 \%$ & $-3.8 \%$ & $+7.7 \%$ \\
\hline & OSMOSE (R1MOX) & $(\mathrm{n}, \gamma)$ & $\pm 2.4 \%$ & $-4.2 \%$ & $+7.3 \%$ \\
\hline & OSMOSE (R1U02) & ${ }^{241} \mathrm{Pu}$ ageing & $\pm 3.1 \%$ & $-10.6 \%$ & $-1.8 \%$ \\
\hline \multirow[t]{3}{*}{ EOLE } & FUBILA & $\mathrm{Pu}$ ageing & $\pm 4.0 \%$ & $-3.1 \%$ & $+5.3 \%$ \\
\hline & MISTRAL3 & $\mathrm{Pu}$ ageing & $\pm 3.0 \%$ & $-4.0 \%$ & $+4.4 \%$ \\
\hline & ERASME-R & $(\mathrm{n}, \mathrm{f})$ & $\pm 7.2 \%$ & $+9.5 \%$ & $+0.7 \%$ \\
\hline
\end{tabular}

within the upper limit of the experimental uncertainties.

For the fission cross section, we use an integral trend based on fission rates measured with fission chambers placed in the center of the ERASME-R configuration. The latter program was performed in the EOLE facility to study fundamental lattice parameters associated with the use of MOX fuel in undermoderated spectrum.

The integral trends collected during the benchmarking of the ${ }^{241}$ Am resonance parameters are listed in Table 4 . A better agreement between the calculations and the experimental results is achieved with the latest JEFF-3.2 library. One of the remaining ambiguous results concerns the new trend observed for the OSMOSE experiment $(\simeq+7 \%)$. It is not consistent with the calculation of the ${ }^{241} \mathrm{Pu}$ ageing. Two experiments are under investigation for solving this problem. The first one will use the oscillating technique in the MINERVE facility with new ${ }^{241} \mathrm{Am}$ samples previously used at the IRMM to measure the ${ }^{241} \mathrm{Am}(\mathrm{n}, 2 \mathrm{n})$ cross section [27]. The second one will consists to perform transmission measurements at the IRMM with the MINERVE samples.

\section{Integral benchmarks}

Several experimental programs were conducted by CEA to investigate the use of MOX fuel in commercial PWRs or innovative concepts for various moderation ratios. In the EOLE facility, integral experiments with MOX fuel 
Table 5

(C-E) results in pcm obtained with the TRIPOLI and MVP codes.

\begin{tabular}{lcccc}
\hline EOLE & \multicolumn{2}{c}{ TRIPOLI4 } & \multicolumn{2}{c}{ MVP } \\
Configurations & with JEFF-3.1.1 & with JENDL-3.2 \\
\hline MH1.2 & $+51(6)$ & {$[22]$} & $+220(20)$ & {$[42]$} \\
FUBILA Ref & $+119(8)$ & {$[45]$} & $+270(20)$ & {$[44]$} \\
MISTRAL-2 Ref & $+597(8)$ & {$[40]$} & $+640(20)$ & {$[42]$} \\
MISTRAL-3 Ref & $+640(8)$ & {$[40]$} & $+700(20)$ & {$[42]$} \\
MISTRAL-4 Ref & $+735(8)$ & {$[40]$} & $+880(20)$ & {$[42]$} \\
\hline
\end{tabular}

started in 1984 with the ERASME program devoted to High-Conversion LWRs (under-moderated MOX lattices) [28]. These HCLWR studies were followed in 1989 by the EPICURE 30\% MOX recycling program in standard PWR $[29,30]$. The MISTRAL programs (MISTRAL-2, MISTRAL-3 and MISTRAL-4), devoted to $100 \%$ MOX recycling in advanced PWR, were undertaken between 1997 to 2000 [31-40]. Finally, the BASALA (2000-2003) and FUBILA (20052006) programs were designed to study MOX core configurations for BWR Physics [41,43-45]. These programs and their main achievements are described elsewhere [46].

We have focused our attention on the MH1.2 configuration of the EPICURE program, on the MISTRAL-2-3-4 configurations and on the FUBILA program. Results obtained with the Monte-Carlo code TRIPOLI and the JEFF-3.1.1 library are expressed in term of $\Delta \rho=C-E$, where $E$ and $C$ stand for the experimental and calculated reactivities, respectively. Owing to the collaboration with the Japanese organisms (NUPEC and JNES), complementary calculations were performed with the Monte-Carlo code MVP [47] with the Japanese Library JENDL. Results are summarized in Table 5.

\subsection{PWR mixed-oxide fuel experiments MH1.2 in the EPICURE program}

The EPICURE program (1989-1994) was jointly agreed upon 1988 by the CEA and its industrial partners. This program consisted in 5 configurations (UH1.2, UH1.4, UH1.4-abs, MH1.2, UM-17 × 17, UM-Zone). They provide a complete and high-quality experimental database for evaluating the uncertainties in reactor physics calculations of plutonium-recycling PWRs.

The present work focuses on the mixed uranium-plutonium core MH1.2. The central zone was composed of MOX fuel pins ( $7 \%$ enrichment). The reactivity is correctly predicted with the JEFF-3.1.1 library: 


$$
\Delta \rho(\mathrm{MH} 1.2)=+51 \pm 260 \mathrm{pcm} .
$$

The experimental uncertainty of $\pm 260 \mathrm{pcm}(1 \sigma)$ involves the measurement uncertainty of the core residual reactivity and the technological uncertainties (fuel density, $\mathrm{Pu}$ composition, overclad diameter, lattice pitch).

During the evaluation work, particular attention had to be paid to this result in order to maintain the good agreement with the experimental value.

\subsection{MISTRAL program for high-moderation $100 \%$ MOX core physics}

The MISTRAL program (MOX investigation of Systems which are Technically Relevant of Advanced Light water reactors) was carried out in the EOLE reactor in the frame of a broad collaboration between NUPEC (Japanese government-sponsored corporation), CEA and their associated industrial partners. It was designed to measure the main neutronic parameters of interest for Advanced Light Water Reactors with high moderation 100\% MOX fuel cores. The configurations of interest for this work are MISTRAL-2 (19971998), MISTRAL-3 (1998-1999) and MISTRAL-4 (1999-2000). MISTRAL-2 and MISTRAL-3 are regular cores, whereas MISTRAL-4 consists of a mock-up of $17 \times 17$ overmoderated assemblies.

The MISTRAL-2 configuration was a highly moderated full-MOX core consisting of about 1600 MOX (7\% enrichment) fuel pins in a lattice pitch of $1.32 \mathrm{~cm}$. The criticality was obtained by adjusting the number of fuel pins. The core configuration of MISTRAL-3 was devoted to the physical study of a 100\% MOX lattice with higher moderation than MISTRAL-2. This configuration consisted of about 1350 MOX $7 \%$ fuel pins in the lattice pitch of 1.39 $\mathrm{cm}$. In that case, the criticality was obtained by adjusting the soluble boron concentration. The fourth configuration, MISTRAL-4, has been studied for the third generation of LWRs in order to alow 100\% MOX recycling.

Several parameters were measured and investigated (critical mass, boron concentration, buckling measurement using reaction rate distribution measurements, pin-by-pin fission maps, boron worth, spectrum indices measurement, modified conversion factor, isothermal temperature coefficients, reactivity worth of several absorbers, void coefficient). In this work, we limit ourselves to $k_{\text {eff }}$ calculations. Results obtained with the JEFF-3.1.1 library show an increasing discrepancy with the $\mathrm{Pu}$-ageing between the experimental and the calculated reactivity:

$$
\Delta \rho \text { (MISTRAL-2 Ref. })=+597 \pm 220 \text { pcm }
$$




$$
\begin{aligned}
& \Delta \rho \text { (MISTRAL-3 Ref. })=+640 \pm 210 \mathrm{pcm} . \\
& \Delta \rho \text { (MISTRAL-4 Ref. })=+735 \pm 250 \mathrm{pcm} .
\end{aligned}
$$

\subsection{MOX core configurations in the FUBILA program for BWR Physics}

The FUBILA program was a first-of-a-kind full MOX core physics experiment with actual BWR fuel pins undertaken by CEA and JNES (Japanese organism). Eight different core configurations (2005-2006) were designed to obtain core physics data of high burn up for $9 \times 9$ and $10 \times 10$ BWR MOX assemblies.

The experimental region was composed of four full MOX BWR assemblies placed in the center of the EOLE core tank. The BWR type MOX rods were specifically fabricated for this program in the MOX fabrication plant MELOX located in CEA Marcoule. They are composed of MOX pellets of Pu enrichments of 3.0, 5.0, 8.5 and $11.5 \%$. In January 2005, the Pu composition was ${ }^{238} \mathrm{Pu}(2 \%),{ }^{239} \mathrm{Pu}(56 \%),{ }^{240} \mathrm{Pu}(25 \%),{ }^{241} \mathrm{Pu}(9 \%),{ }^{242} \mathrm{Pu}(9 \%)$ and ${ }^{241} \mathrm{Am}$ (1\%). The experimental region was surrounded by a driver region composed of EPICURE MOX rods (7.0\% enrichment) with the following Pu composition: ${ }^{238} \mathrm{Pu}(1 \%),{ }^{239} \mathrm{Pu}(58 \%),{ }^{240} \mathrm{Pu}(25 \%),{ }^{241} \mathrm{Pu}(5 \%),{ }^{242} \mathrm{Pu}(5 \%)$ and ${ }^{241} \mathrm{Am}$ (6\%) (January 2005).

The reference configuration of the FUBILA program is of great interest because the experimental zone was composed of fresh mixed oxide fuel while the driven zone is characterized by a large content of ${ }^{241} \mathrm{Am}$. As a consequence, we expect to have $\Delta \rho$ results of similar magnitude between the reference configuration of FUBILA and the MH1.2 configuration (section 4.1). TRIPOLI calculations based on the JEFF-3.1.1 library confirm this assumption:

$$
\Delta \rho \text { (FUBILA Ref. })=+119 \pm 250 \mathrm{pcm} .
$$

\section{$5 \quad$ Results and discussions}

\subsection{Reactivity effect breakdown calculations}

This section aims at presenting the origins of the discrepancies observed on $\Delta \rho$ (section 4) based on reactivity breakdown calculations performed in Ref. [48]. Table 6 shows the evolution of the plutonium isotopic vector with the $\mathrm{Pu}$ ageing for standard MOX fuel. The production of americium in MOX fuel pins is illustrated over a large time scale that corresponds to the beginning 
Table 6

Evolution of the $\mathrm{Pu}$ isotopic vector with the $\mathrm{Pu}$ ageing for standard MOX fuel corresponding to recycled UO2 fuel for a burnup of $33 \mathrm{GWd} / \mathrm{t}, t_{0}$ being the begining of irradiation.

\begin{tabular}{ccc}
\hline Isotopes & $t_{0}$ & $t_{0}+20$ years \\
\hline${ }^{238} \mathrm{Pu}$ & $2.1 \%$ & $1.8 \%$ \\
${ }^{239} \mathrm{Pu}$ & $55.8 \%$ & $56.2 \%$ \\
${ }^{240} \mathrm{Pu}$ & $25.2 \%$ & $25.43 \%$ \\
${ }^{241} \mathrm{Pu}$ & $8.8 \%$ & $3.1 \%$ \\
${ }^{242} \mathrm{Pu}$ & $6.6 \%$ & $6.6 \%$ \\
${ }^{241} \mathrm{Am}$ & $1.5 \%$ & $7.0 \%$ \\
\hline
\end{tabular}

Table 7

Isotopic uncertainty components as a function of the $\mathrm{Pu}$ ageing for standard EPICURE MOX fuel pins (4.3\% enrichment). The calculations were performed with the exact perturbation formalism implemented in the PARIS code $[49,50]$ by using the cross-sections covariance matrices COMAC [51], excepted for ${ }^{241} \mathrm{Am}$. For this isotope, the uncertainty was increased to account for the underestimation of the capture resonance integral by at least $20 \%$ (see Table 3 ).

\begin{tabular}{cccc}
\hline Isotopes & $t_{0}$ & $t_{0}+20$ years & $\Delta$ \\
\hline${ }^{235} \mathrm{U}$ & $16 \mathrm{pcm}$ & $18 \mathrm{pcm}$ & $+2 \mathrm{pcm}$ \\
${ }^{238} \mathrm{U}$ & $260 \mathrm{pcm}$ & $263 \mathrm{pcm}$ & $+3 \mathrm{pcm}$ \\
${ }^{239} \mathrm{Pu}$ & $802 \mathrm{pcm}$ & $895 \mathrm{pcm}$ & $+93 \mathrm{pcm}$ \\
${ }^{240} \mathrm{Pu}$ & $70 \mathrm{pcm}$ & $73 \mathrm{pcm}$ & $+3 \mathbf{p c m}$ \\
${ }^{241} \mathrm{Pu}$ & $\mathbf{1 2 5} \mathbf{~ p c m}$ & $\mathbf{5 0 ~ p c m}$ & $\mathbf{- 7 5} \mathbf{~ p c m}$ \\
${ }^{242} \mathrm{Pu}$ & $132 \mathrm{pcm}$ & $132 \mathrm{pcm}$ & - \\
${ }^{241} \mathrm{Am}$ & $>\mathbf{2 0 0 ~ p c m}$ & $>\mathbf{9 0 0} \mathbf{~ p c m}$ & $>+\mathbf{7 0 0 ~} \mathbf{~ c m}$ \\
${ }^{1} \mathrm{H}$ & $41 \mathrm{pcm}$ & $44 \mathrm{pcm}$ & $+3 \mathbf{p c m}$ \\
${ }^{16} \mathrm{O}$ & $44 \mathrm{pcm}$ & $46 \mathrm{pcm}$ & $+2 \mathrm{pcm}$ \\
${ }^{27} \mathrm{Al}$ & $23 \mathrm{pcm}$ & $23 \mathrm{pcm}$ & - \\
\hline
\end{tabular}

of the EPICURE program (section 4.1) to the end of the FUBILA program (section 4.3). Twenty years after the fabrication of the EPICURE MOX fuel pins, the ${ }^{241} \mathrm{Am}$ content is nearly equivalent to the initial content of ${ }^{241} \mathrm{Pu}$.

Table 7 shows the decomposition of the nuclear data uncertainty components per isotope for standard EPICURE MOX fuel pins (4.3\% enrichment). The calculations were performed with the exact perturbation formalism implemented in the PARIS code $[49,50]$ by using the cross-sections covariance matrices CO- 
MAC [51]. They were developed within the nuclear data activities of the CEA Cadarache. For ${ }^{241} \mathrm{Am}$, the reported uncertainties take into account the results reported in Table 3. The comparison of the capture resonance integral:

$$
\begin{gathered}
I_{\gamma}(\mathrm{JEFF}-311)=1526.4 \text { barns, } \\
I_{\gamma}(\mathrm{JEFF}-32)=1826.1 \text { barns },
\end{gathered}
$$

suggests to apply a relative uncertainty of about $20 \%$ over the whole resolved resonance range.

These results confirm the increasing (decreasing) contribution of ${ }^{241} \mathrm{Am}\left({ }^{241} \mathrm{Pu}\right)$. The contributions of the other uranium, plutonium and light isotopes remain unchanged with the $\mathrm{Pu}$ ageing. The global uncertainty calculated with the covariance data of COMAC is dominated by the ${ }^{239} \mathrm{Pu}$ and ${ }^{241} \mathrm{Am}$ contributions. For ${ }^{241} \mathrm{Am}$, the difference $\Delta>700 \mathrm{pcm}$ calculated between $t_{0}$ and $t_{0}+20$ years is compatible with the $\Delta \rho$ results obtained for the reference configurations of the MISTRAL programs ( $597 \mathrm{pcm}<\Delta \rho<735 \mathrm{pcm}$ ). The trend of the $k_{\text {eff }}$ overestimation from the MH1.2 experiment to the MISTRAL-2/MISTRAL-4 experiments can be partially explained by the increase of the moderation ratio $V_{H_{2} \mathrm{O}} / V_{\text {MOX }}$ from 1.25 to 2.2 . However, the large $k_{\text {eff }}$ shift confirms the underestimation of the ${ }^{241} \mathrm{Am}(\mathrm{n}, \gamma)$ reaction in the JEFF-3.1.1 library. The improvements achieved with JEFF-3.2 are detailed in sections $5.2\left(k_{\text {eff }}\right.$ calculations) and 5.3 (uncertainty propagation calculations).

\subsection{Benchmaking of the JEFF-3.2 library}

Interpretations of the integral experiments carried out in the EOLE facility are routinely performed with the deterministic and Monte-Carlo codes APOLLO2 and TRIPOLI4 [52]. We focus our work on material buckling $B_{m}^{2}$ and critical $k_{\text {eff }}$ measurements.

Results obtained with the JEFF-3.1.1 and JEFF-3.2 libraries are shown in Fig. 6 as a function of the $\mathrm{Pu}$ ageing. The reactivity of $\mathrm{Pu}$-fueled lattices calculated with the APOLLO2 code within the fundamental mode hypothesis is mainly checked through material buckling values deduced from radial and axial flux measurements. Three results are reported for the MH1.2, MISTRAL2 and MISTRAL-3 programs.

The MVP code provide results consistent with those calculated with the TRIPOLI4 code. The observed trend confirms the increasing discrepancies with the $\mathrm{Pu}$ ageing between the calculations and the experiments. The worst result reaches a maximum close to $\Delta \rho \simeq+800$ pcm for the reference configuration of the MISTRAL-4 program carried out in 1999. This trend is explained 


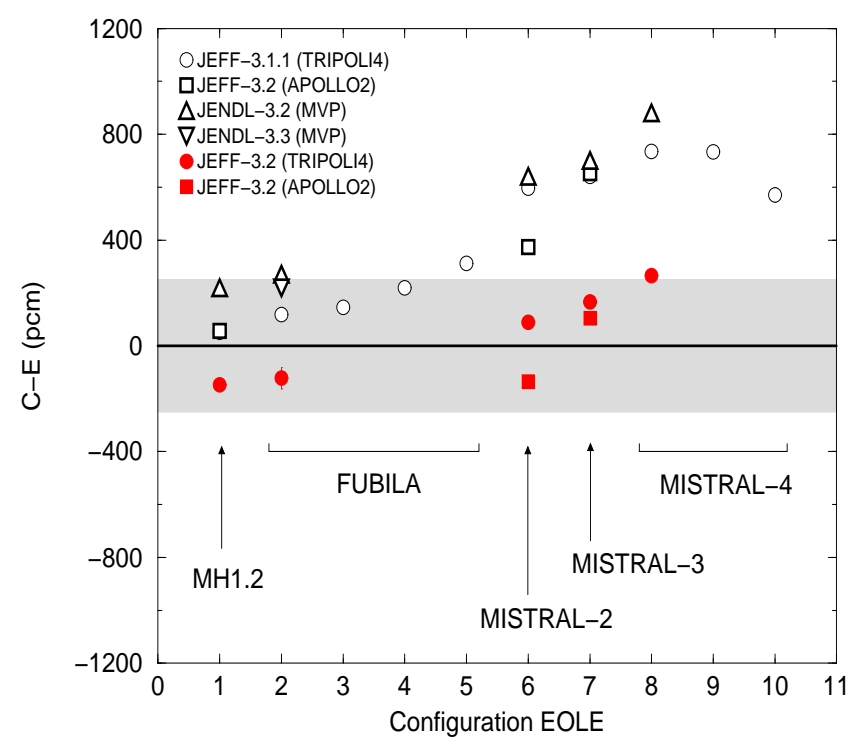

Fig. 6. Integral trends obtained with the JEFF-3.1.1, JENDL-3.2 and JEFF-3.2 libraries for material buckling $B_{m}^{2}$ (APOLLO2 calculations) and critical $k_{\text {eff }}$ measurements (TRIPOLI and MVP calculations).

with the perturbation calculations reported in section 5.1.

The latest version of the JEFF library (JEFF-3.2) improves significantly the reactivity calculations of MOX configurations over a wide range of moderation ratios. The mean value $\langle\Delta \rho\rangle$ calculated over the five reference configurations of the FUBILA, MH1.2 and MISTRAL-2-3-4 programs becomes:

$$
\langle\Delta \rho\rangle=+50 \mathrm{pcm}
$$

with a standard deviation of:

$$
\sigma_{\langle\Delta \rho\rangle}=180 \mathrm{pcm}
$$

This satisfactory trend is mainly achieved due to the new ${ }^{241} \mathrm{Am}$ evaluation performed in collaboration with the IRMM (section 3.2). The capture resonance integral was increased by $20 \%$ (Table 3 ). The impact of the ${ }^{239} \mathrm{Pu}$ evaluation (section 3.1) and of the whole JEFF-3.2 library can be deduced from the reference configuration of FUBILA and from the MH1.2 configuration of EPICURE because their experimental zone was composed of MOX fuel pins characterized by a low americium content $(<2 \%)$. The $\Delta \rho$ values of $-148(6)$ pcm and $-122(40)$ pcm remain within the limit of the benchmark uncertainties $( \pm 250 \mathrm{pcm})$. These results satisfy the non-regression principle established for improving the JEFF library. 


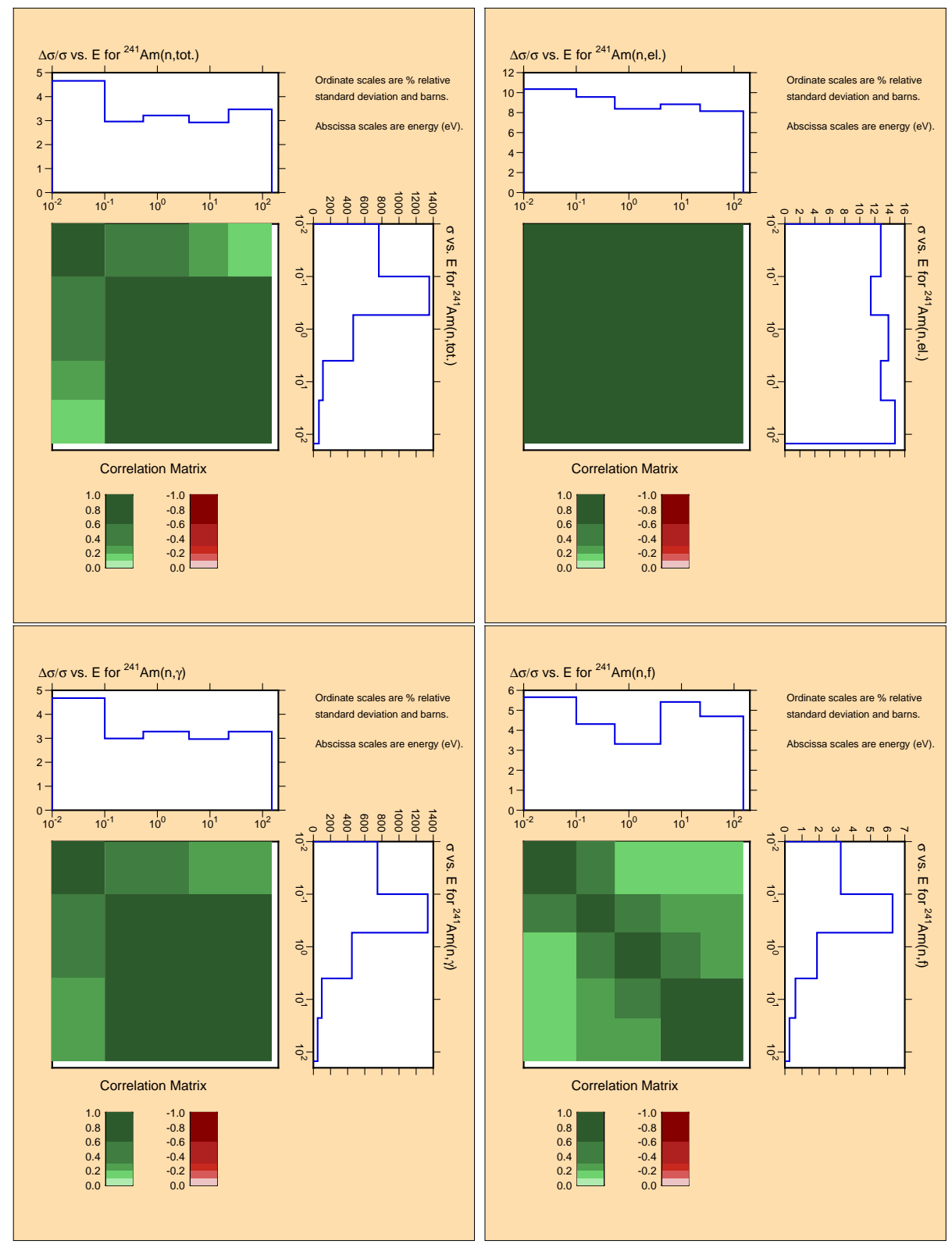

Fig. 7. Relative uncertainties and correlation matrices for the neutron induced reactions on ${ }^{241} \mathrm{Am}$ up to $150 \mathrm{eV}$ from JEFF-3.2 [26].

\subsection{Propagation and reduction of the nuclear data uncertainties}

This section presents the propagation of the resonance parameter uncertainties on the calculated $k_{\text {eff }}$. Owing to the results of the nuclear data uncertainty calculations presented in Table 7, we have focused our attention on the ${ }^{239} \mathrm{Pu}$ and ${ }^{241} \mathrm{Am}$ contributions. A Monte-Carlo propagation technique was applied on the MISTRAL benchmarks calculated with the APOLLO2 code. Detailed explanations are given in Ref. [53]. Similar technique was used to propagate the ${ }^{237} \mathrm{~Np}$ nuclear data uncertainties on oscillation measurements performed 


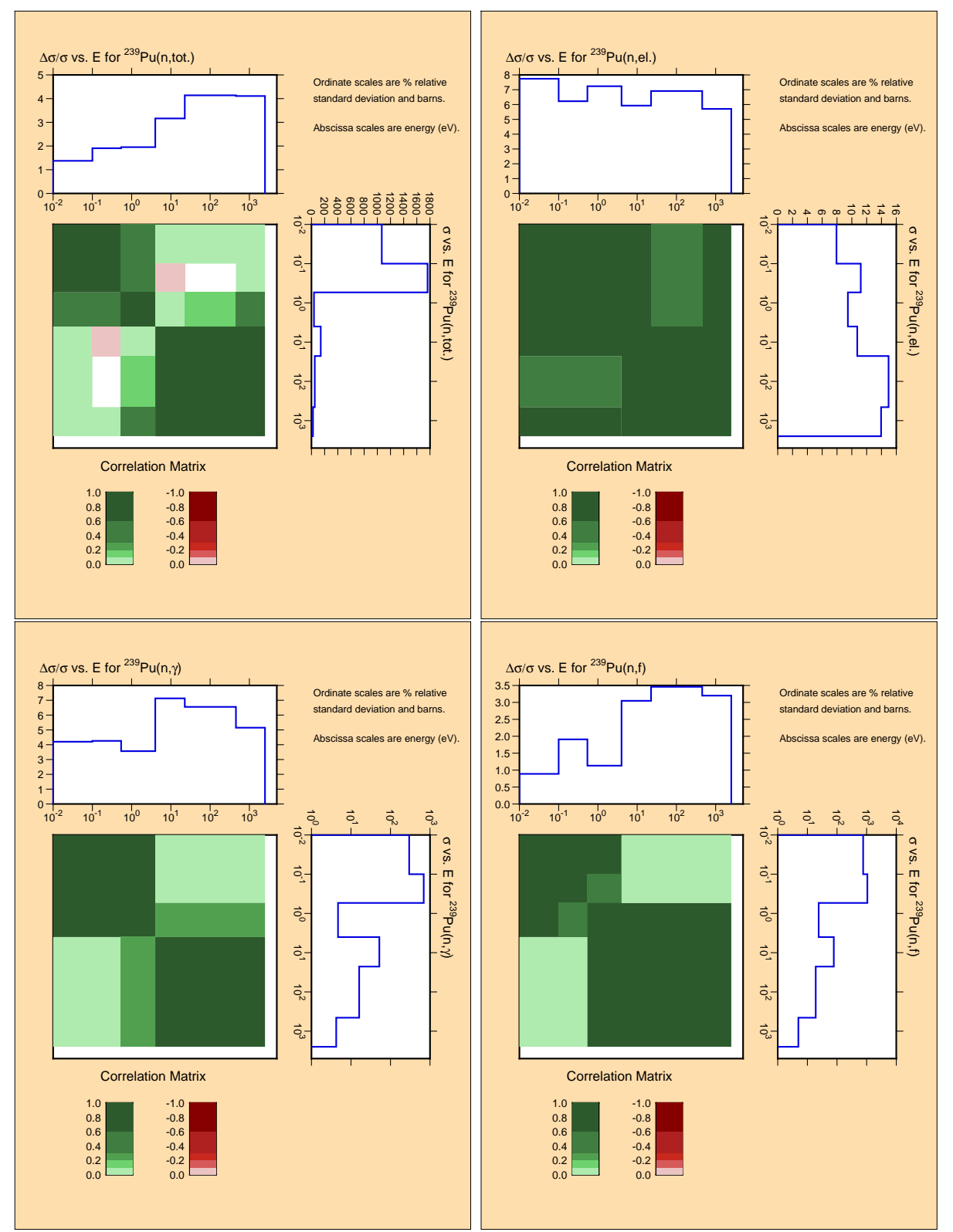

Fig. 8. Relative uncertainties and correlation matrices for the neutron induced reactions on ${ }^{239} \mathrm{Pu}$ up to $2.5 \mathrm{keV}$ from JEFF-3.2 [20].

in the MINERVE facility [54].

The Resonance Parameter Covariance Matrices (RPCM) for ${ }^{239} \mathrm{Pu}$ and ${ }^{241} \mathrm{Am}$ were generated by using the marginalization procedure implemented in the CONRAD code. The marginalization technique consists of distinguishing the contributions of the "statistical" and "systematic" uncertainties during the evaluation of the resonance parameters. The "statistical" uncertainties are mainly related to uncertainties that do not produce long range correlations. The "systematic" uncertainties represent the uncertainties of experimental corrections such as the sample composition and the normalization used in 

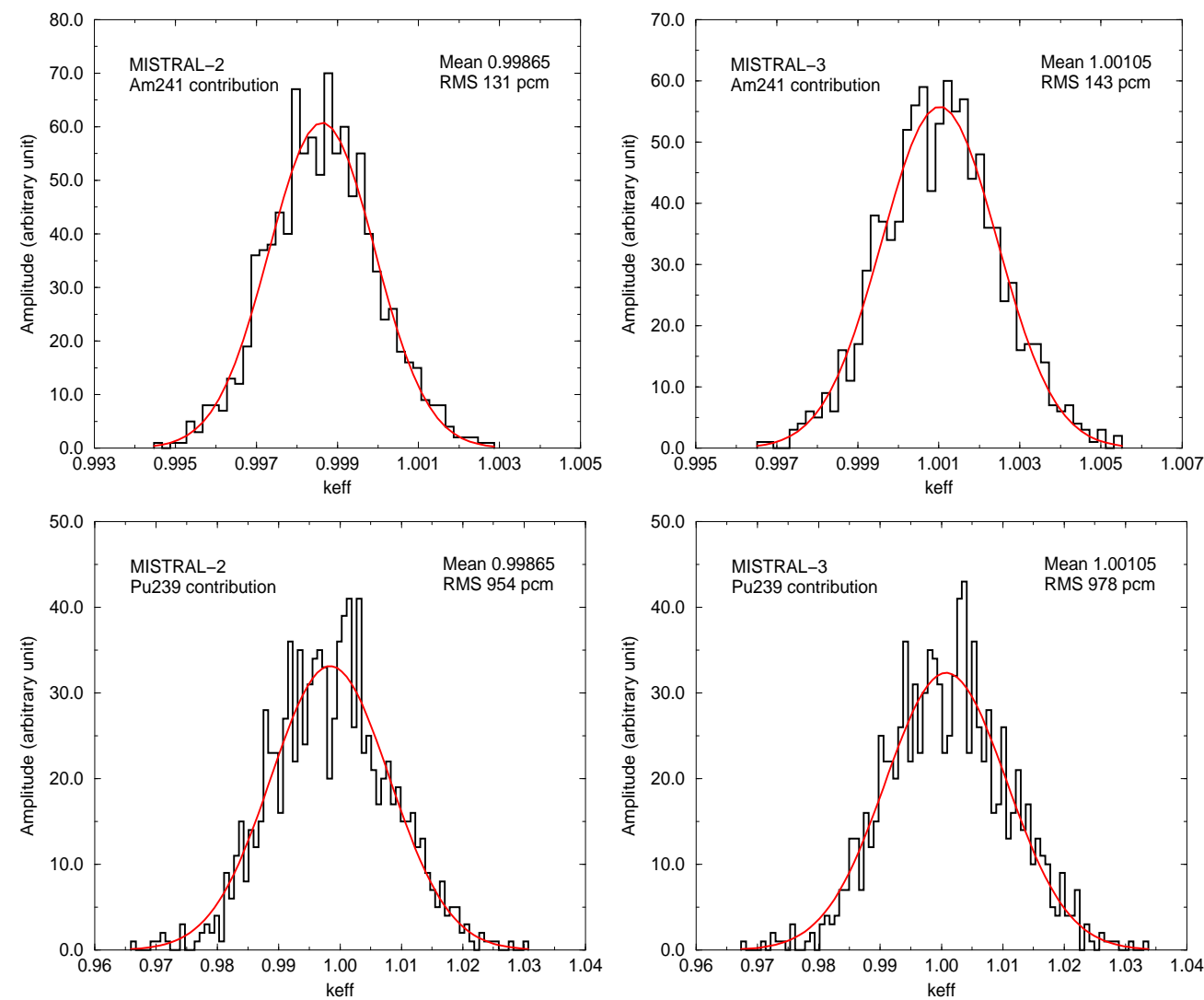

Fig. 9. Distributions of the $k_{\text {eff }}$ values obtained by Monte-Carlo for the MISTRAl-2 and MISTRAL-3 experiments by using the ${ }^{241} \mathrm{Am}$ and ${ }^{239} \mathrm{Pu}$ Resonance Parameter Covariance Matrix of JEFF-3.2.

Table 8

Uncertainties on $k_{\text {eff }}$ calculated by Monte-Carlo by using the ${ }^{241} \mathrm{Am}$ and ${ }^{239} \mathrm{Pu}$ covariance data available in the JEFF-3.2 library. These results take only into account the uncertainties on the resonance parameters.

\begin{tabular}{cccc}
\hline Isotopes & MISTRAL-2 & MISTRAL-3 & $\Delta$ \\
\hline${ }^{241} \mathrm{Am}$ & $\pm 131 \mathrm{pcm}$ & $\pm 143 \mathrm{pcm}$ & $+12 \mathrm{pcm}$ \\
${ }^{239} \mathrm{Pu}$ & $\pm 954 \mathrm{pcm}$ & $\pm 978 \mathrm{pcm}$ & $+24 \mathrm{pcm}$ \\
\hline
\end{tabular}

time-of-flight measurements. Relative uncertainties on total, capture, fission and elastic cross sections calculated over a broad energy mesh (15 groups) are shown in Figs. 7 and 8.

Impacts of the nuclear data uncertainties on the calculated lattice reactivity were investigated on the MISTRAL-2 and MISTRAL-3 configurations. The Monte-Carlo calculations were performed based on the Cholesky decomposition of the Resonance Parameter Covariance Matrices assuming the resonance parameters to be Gaussian distributed. Results obtained from 1000 APOLLO2 calculations are displayed on Fig. 9. The standard deviation of each distribution is reported in Table 8 . For ${ }^{241} \mathrm{Am}$, the contribution of the resonance 
Table 9

Comparison between the relative uncertainties on the ${ }^{239} \mathrm{Pu}$ capture cross section, fission cross section and thermal quantities calculated with JEFF-3.2 and obtained in this work (target accuracy).

\begin{tabular}{|c|c|c|c|c|c|}
\hline \multirow{2}{*}{\multicolumn{3}{|c|}{$\begin{array}{c}\text { Energy range } \\
(\mathrm{eV})\end{array}$}} & \multirow{3}{*}{$\begin{array}{c}(\mathrm{n}, \gamma) \\
\text { JEFF-3.2 } \\
297.3 \text { barns }\end{array}$} & \multicolumn{2}{|c|}{ Relative uncertainty } \\
\hline & & & & \multirow{2}{*}{$\frac{\mathrm{JEFF}-3.2}{4.3 \%}$} & \multirow{2}{*}{$\frac{\text { Target accuracy }}{2.5 \%}$} \\
\hline & $<$ & 0.1 & & & \\
\hline 0.1 & - & 0.54 & 693.9 barns & $4.4 \%$ & $2.5 \%$ \\
\hline 0.54 & - & 4.0 & 4.7 barns & $3.7 \%$ & $2.0 \%$ \\
\hline 4.0 & - & 22.6 & 52.2 barns & $6.9 \%$ & $6.9 \%$ \\
\hline 22.6 & - & 454.0 & 16.1 barns & $6.8 \%$ & $6.8 \%$ \\
\hline 454.0 & - & 2500.0 & 4.2 barns & $5.6 \%$ & $5.6 \%$ \\
\hline
\end{tabular}

\begin{tabular}{|c|c|c|c|c|c|}
\hline \multirow{2}{*}{\multicolumn{3}{|c|}{$\begin{array}{c}\text { Energy range } \\
(\mathrm{eV})\end{array}$}} & \multirow{3}{*}{$\begin{array}{c}(\mathrm{n}, \mathrm{f}) \\
\text { JEFF-3.2 } \\
762.6 \text { barns }\end{array}$} & \multicolumn{2}{|c|}{ Relative uncertainty } \\
\hline & & & & \multirow{2}{*}{$\frac{\mathrm{JEFF}-3.2}{0.9 \%}$} & \multirow{2}{*}{$\frac{\text { Target accuracy }}{0.9 \%}$} \\
\hline & $<$ & 0.1 & & & \\
\hline 0.1 & - & 0.54 & 1057.9 barns & $1.9 \%$ & $1.7 \%$ \\
\hline 0.54 & - & 4.0 & 24.1 barns & $1.2 \%$ & $1.2 \%$ \\
\hline 4.0 & - & 22.6 & 77.9 barns & $3.1 \%$ & $3.0 \%$ \\
\hline 22.6 & - & 454.0 & 19.1 barns & $3.5 \%$ & $3.5 \%$ \\
\hline 454.0 & - & 2500.0 & 5.0 barns & $3.4 \%$ & $3.3 \%$ \\
\hline \multirow{2}{*}{\multicolumn{3}{|c|}{$\begin{array}{l}\text { Thermal } \\
\text { quantities }\end{array}$}} & Value & \multicolumn{2}{|c|}{ Relative uncertainty } \\
\hline & & & JEFF-3.2 & JEFF-3.2 & Target accuracy \\
\hline \multicolumn{3}{|c|}{$\sigma_{f}$} & 747.2 barns & $0.9 \%$ & $0.9 \%$ \\
\hline \multicolumn{3}{|c|}{$\sigma_{\gamma}$} & 270.1 barns & $4.4 \%$ & $2.5 \%$ \\
\hline \multicolumn{3}{|c|}{$I_{f}$} & 308.8 barns & $2.3 \%$ & $2.3 \%$ \\
\hline \multicolumn{3}{|c|}{$I_{\gamma}$} & 180.1 barns & $5.7 \%$ & $5.7 \%$ \\
\hline \multicolumn{3}{|c|}{ K1 } & 1161.5 barns & $1.7 \%$ & $1.0 \%$ \\
\hline
\end{tabular}

parameter uncertainties reaches $131 \mathrm{pcm}$ for MISTRAL-2 and $143 \mathrm{pcm}$ for MISTRAL-3. The magnitude of the ${ }^{241} \mathrm{Am}$ contribution is significantly improved compared to the contribution of about $900 \mathrm{pcm}$ reported in Table 7 . By contrast, the ${ }^{239} \mathrm{Pu}$ resonance parameter uncertainties available in JEFF3.2 still lead to a non-negligible contribution slightly greater than $900 \mathrm{pcm}$, in 

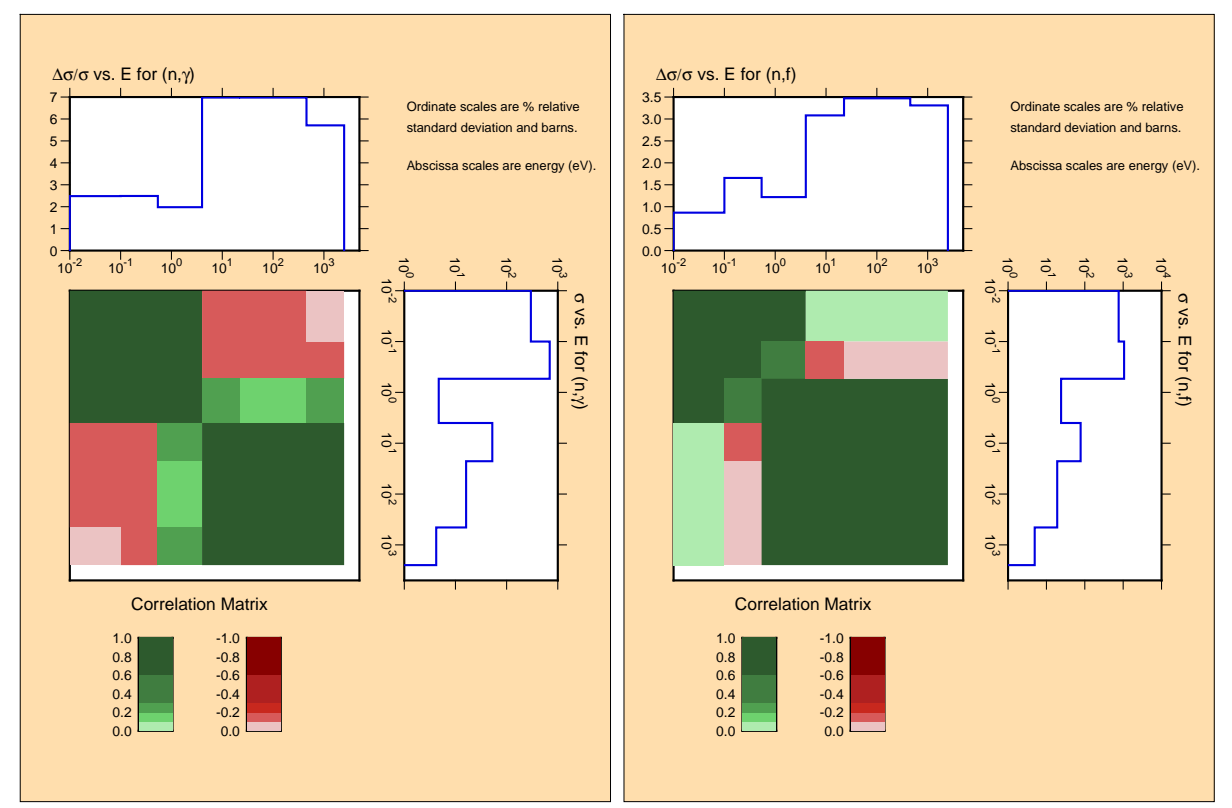

Fig. 10. Final relative uncertainty and correlation matrix for the ${ }^{239} \mathrm{Pu}$ capture and fission cross sections (up to $2.5 \mathrm{keV}$ ) obtained from our Monte-Carlo uncertainty reduction procedure.

agreement with the result provided by the deterministic approach $(895 \mathrm{pcm}$ in Table 7). Such a result is dominated by the uncertainty of the ${ }^{239} \mathrm{Pu}(\mathrm{n}, \gamma)$ reaction. The latter ranges from $4 \%$ to $7 \%$ up to $2.5 \mathrm{keV}$ (Figure 8 ).

A reduction of the uncertainties affecting the accuracy of the ${ }^{239} \mathrm{Pu}$ cross sections can be achieved through appropriate rejection criteria. Such a procedure could become a powerful Integral Data Assimilation technique when a large number of experimental results is included in the analysis. In the present work, we aim only to establish a raw estimate of the target accuracy for the ${ }^{239} \mathrm{Pu}$ cross section uncertainties in order to get an overall ${ }^{239} \mathrm{Pu}$ contribution of about $400 \mathrm{pcm}$. Final results corresponding to this criteria are reported in Table 9. The capture cross section uncertainty is reduced by $2 \%$ up to $4 \mathrm{eV}$ without changing the uncertainty on the fission cross section. The MonteCarlo procedure also provide useful feedbacks and guidelines on the thermal quantities, resonance integrals and equivalent $\mathrm{K} 1$ for future evaluation works. The resulting relative uncertainties and correlation matrix for the ${ }^{239} \mathrm{Pu}(\mathrm{n}, \gamma)$ and ${ }^{239} \mathrm{Pu}(\mathrm{n}, \mathrm{f})$ reactions are shown in Fig. 10.

\section{Conclusions}

The evaluation activities performed on the resonance range of the plutonium $\left({ }^{239} \mathrm{Pu},{ }^{240} \mathrm{Pu},{ }^{241} \mathrm{Pu}\right)$ and americium $\left({ }^{241} \mathrm{Am}\right)$ isotopes within the JEFF project are summarized in the present work. Despite the good performances of JEFF- 
3.1.1 on PST benchmarks, integral experiments carried out in the EOLE facility of CEA Cadarache have pointed out sizeable C-E discrepancies on $k_{\text {eff }}$ with the $\mathrm{Pu}$ ageing. The observed trend was successfully corrected by using the latest version of the JEFF library (JEFF-3.2). The agreement between the calculations and the experimental values (reference configurations of MH1.2, MISTRAL and FUBILA programs) is close to $50 \mathrm{pcm}$ on average with a standard deviation of $180 \mathrm{pcm}$. This improvement was achieved via the increase of the ${ }^{241} \mathrm{Am}$ capture cross section $(+20 \%)$ based on the experimental work carried out at the IRMM.

In the case of the MISTRAL programs, uncertainty calculations based on JEFF-3.1.1 covariances have shown the non-negligible contributions $(\simeq 900$ $\mathrm{pcm})$ of the ${ }^{241} \mathrm{Am}$ and ${ }^{239} \mathrm{Pu}$ capture cross section uncertainties. The ${ }^{241} \mathrm{Am}$ contribution to the $k_{\text {eff }}$ uncertainty is significantly reduced $(\simeq 150 \mathrm{pcm}$ ) by using the JEFF-3.2 evaluation together with the corresponding Resonance Parameter Covariance Matrix. By contrast, the ${ }^{239} \mathrm{Pu}$ contribution is not improved with JEFF-3.2 because the ${ }^{239} \mathrm{Pu}$ evaluation was elaborated with capture data whose normalization uncertainty ranges from $4 \%$ to $7 \%$.

A preliminary study performed to provide target accuracies for the ${ }^{239} \mathrm{Pu}(\mathrm{n}, \gamma)$ reaction suggests to decrease the relative uncertainty down to $2 \%$ up to $4 \mathrm{eV}$, leading to a thermal capture cross section of $270.1 \pm 6.8$ barns and an equivalent K1 of $1161.5 \pm 12.0$ barns. These trends could provide useful feedbacks and guidelines for future evaluation works.

\section{Acknowledgements}

This work was supported by the french industrial partners (EDF and AREVA) through the SINET project of the Nuclear Energy Division of CEA. 


\section{References}

[1] R. Sanchez et al., Nucl. Sci. Techn. 42, 474 (2010).

[2] J.P. Both, Tripoli4 - A three dimensional polykinetic particle transport Monte Carlo code., in Proc. Int. Conf. on Supercomputing in Nuclear Applications, SNA2003, Paris, France, 2003.

[3] A. Santamarina et al., The JEFF-3.1.1 Nuclear Data Library, JEFF Report 22, 2009.

[4] H. Henriksson et al., The art of collecting experimental data internationally: EXFOR, CINDA and the NRDC network, in Proc. Int. Conf. on Nuclear Data for Science and Technology, ND2007, Nice, France, 2007.

[5] N.M. Larson, Updated User's Guide for SAMMY, Oak Ridge National Laboratory Report ORNL0TM-91790R7, 2006.

[6] H. Derrien et al, Nucl. Sci. Eng. 150, 109 (2005).

[7] J.A. Harvey et al., Solid State Effects on Thermal Neutron Cross Sections and on Low Energy Resonances, in Proc. Int. Conf. on Nuclear Data for Science and Technology, ND1982, Antwerp, Belgium, 1982.

[8] O. Bouland et al, Nucl. Sci. Eng. 127, 105 (1997).

[9] L. San Felice et al., Experimental validation of the DARWIN-2.3 package for fuel cycle applications, in Proc. of the Topical Meeting on Advances in Reactor Physics, PHYSOR2012, Knoxville, USA, 2012.

[10] D. Bernard and O. Bouland, J. Nucl. Sci. Tech. 49, 132 (2012).

[11] T.S. Belanova et al., Translated from Atomnaya Energiya, 38, 29 (1975).

[12] G.G. Slaughter et al., Oak Ridge National Laboratory Report No. ORNL-3085, 1961.

[13] H. Derrien and B. Lucas., The total cross section and the fission cross section of ${ }^{2} 41 \mathrm{Am}$ in the resonance region, resonance parameters, in Proc. of Nuclear Data conference, Washington, USA (1975).

[14] P. Leconte and D. Bernard, OSMOSE programme: Validation of Actinide Nuclear Data for LWR applications, JEFF document JEFFDOC-1502, 2013.

[15] D. Bernard et al., accepted for publication in Nucl. Sci. Eng.

[16] L. Erradi et al., Nucl. Sci. Eng. 144, 47 (2003).

[17] L. Erradi and A. Santamarina, Analysis of the MISTRAL experiment on LWR Reactivity Temperature Coefficient, in Proc. of the Topical Meeting on Advances in Reactor Physics to Power the Nuclear Renaissance, PHYSOR2010, Pittsburgh, USA, 2010. 
[18] S.C. van der Marck, Nucl. Data Sheets 113, 2935 (2012).

[19] S.F. Mughabghab, Atlas of Neutron Resonances, $5^{\text {th }}$ edition (Elsevier, Amsterdam, 2006).

[20] C. De Saint Jean et al., Co-ordinated Evaluation of Plutonium-239 in the Resonance Region, WPEC Report 34, 2014.

[21] L. Leal et al., ${ }^{239} \mathrm{Pu}$ resonance evaluation for thermal benchmark system calculations, in Proc. Int. Conf. on Nuclear Data for Science and Technology, ND2013, New York, USA, 2013.

[22] Y. Peneliau et al., JEFF-3.2T3 benchmarking - Criticality experiments to full reactor calculations, JEFF document JEFFDOC-1583, 2014.

[23] O. Cabellos, Processing and benchmarking of the JEFF32T4 (JEFF-3.2) library (February 2014 Update), JEFF document JEFFDOC-1562, 2014.

[24] Y. Peneliau et al., ${ }^{239} \mathrm{Pu}$ Prompt Fission Neutron Spectra Impact on a Set of Criticality and Experimental Reactors Benchmarks, in Proc. Int. Conf. on Nuclear Data for Science and Technology, ND2013, New York, USA, 2013.

[25] C. Lampoudis et al., Eur. Phys. J. Plus 128, 86 (2013).

[26] G. Noguere et al., to be published in Phys. Rev. C.

[27] C. Sage et al., Phys. Rev. C 81, 064604 (2010).

[28] A. Santamarina et al., Undermoderated PWR neutronic qualification through the ERASME experiment, in Proc. of the Topical Meeting on Advances in Reactor Physics, Paris, France, 1987.

[29] J. Mondot et al., EPICURE : an experimental program devoted to the validation of the calculational schemes for plutonium recycling in PWRs, in Proc. of the Int. Conf. on the Physics of Reactors : Operation Design and Computation, Marseille, France, 1990.

[30] P. Fougeras et al., Nucl. Sci. Eng. 121, 32 (1995).

[31] S. Cathalau et al., MISTRAL: an experimental program in the EOLE facility devoted to $100 \%$ MOX core physics, in Proc. Int. Conf. on Physics of Reactors, PHYSOR1996, Mito, Japan, 1996.

[32] T. Yamamoto et al., Core Physics experiment of 100\% MOX core MISTRAL, in Proc. Int. Conf. on Future Nuclear Systems, Yokohama, Japan, GLOBAL'97, 1997.

[33] S. Cathalau et al., First validation of neutronic lattice parameters of over moderated 100\% MOX fuelled PWR cores on the basis of the MISTRAL experiment, in Proc. Int. Conf. on the Physics of Nuclear Science and Technology: future Nuclear Systems, Long Island, USA, 1998.

[34] P. Fougeras et al., MISTRAL-4 : an experimental mockup in the EOLE facility devoted to high moderation 100\% MOX core Physics, in Proc. Int. Conf on the Future Nuclear Systems, GLOBAL'99, Jackson Hole, USA, 1999. 
[35] K. Hibi et al., Analysis of MISTRAL and EPICURE experiments with SRAC and MVP code systems, in Proc. Int. Conf. Physics of Reactor Operation, Design and Computation, PHYSOR2000, Pittsburg, USA, 2000,

[36] M. Tatsumi et al., Analysis of High Moderation PWR MOX Core MISTRAL-4 with SRAC and MVP, in Proc. Int. Conf. on Nuclear Data for Science and Technology, ND2001, Tsukuba, Japan, 2001.

[37] T. Yamamoto et al., Analysis of MISTRAL Experiments with JENDL-3.2, in Proc. Int. Conf. on Nuclear Data for Science and Technology, ND2001, Tsukuba, Japan, 2001.

[38] S. Cathalau et al., Full MOX recycling in ALWR : Lessons Drawn through the MISTRAL Program, in Proc. Int. Conf. PHYSOR2002, Seoul, Korea, 2002.

[39] O. Litaize et al., Analysis of the MISTRAL experiment with APOLLO2 qualification of neutronic parameters of UOX and MOX cores, in Proc. Int. Conf. PHYSOR2002, Seoul, Korea, 2002.

[40] P. Blaise and P. Fougeras, Monte Carlo modeling of MISTRAL-4 100\% MOX $17 \times 17$ ALWR mock-up cores using TRIPOLI-4.6, in Proc. of the $2^{\text {nd }}$ Int. Conf. on Physics and Technology of Reactors and Applications, PHYTRA, Fez, Morocco, 2011.

[41] T. Yamamoto et al., BASALA: Advanced BWR MOX core physics experiments, in Proc. of Int. Conf. on Advances in Reactor Physics and Mathematics, PHYSOR2000, Pittsburgh, USA, 2000.

[42] T. Yamamoto et al., BWR MOX Core Physics Experiments and Preliminary Analysis, in Proc. of the ANS Topical Meeting on Reactor Physics, PHYSOR2002, Seoul, Korea, 2002.

[43] T. Yamamoto et al., FUBILA: core physics experimental program aimed at validation of core analysis method for high burn up BWR full MOX cores, in Proc. Int. Conf. GLOBAL'05, Tsukuba, Japan, 2005.

[44] T. Yamamoto et al., Experimental results and analysis of core physics experiments, FUBILA, for high burn-up BWR full MOX cores, in Proc. of the ANS Topical Meeting on Reactor Physics, PHYSOR2006, Vancouver, Canada, 2006.

[45] P. Blaise et al., J. Nucl. Sci. Tech. 47, 1 (2010).

[46] P. Blaise et al., 12 years of Franco-Japanese instrumental program in EOLE for the validation of $100 \%$ MOX recycling in ALWRS, in Proc. of the ANS Topical Meeting on Reactor Physics, PHYSOR2014, Kyoto, Japan, 2014.

[47] Y. Nagaya et al., MVP/GMVP II: general purpose Monte Carlo codes fro neutron and photon transport calculations based on continuous energy and multigroup methods, Report JAERI-1348, 2005.

[48] N. Dos Santos, Optimisation de lapproche de representativite et de transposition pour la conception neutronique de programmes experimentaux dans les maquettes critiques, PhD Thesis, University of Grenoble, France, 2013. 
[49] L. Gastaldo et al., High-order discrete ordinate transport in non-confirming 2D cartesian meshes, in Proc. Int. Conf. on Advances in Mathematics, Computational Methods, and Reactor Physics, Saratoga Springs, USA, 2009.

[50] R. Le Tellier et al., Nucl. Sci. Eng. 167, 209 (2011).

[51] C. De Saint Jean et al., Estimation of multi-group cross section covariances, in Proc. of the ANS Topical Meeting on Reactor Physics, PHYSOR2012, Knoxville, USA, 2012.

[52] A. Santamarina et al., Validation of the new code package APOLLO2.8 for accurate PWR calculations, in Proc. Int. Conf. on Mathematics and Computation, M\&C2013, Sun Valley, USA, 2013.

[53] G. Noguere and J-C. Sublet, Ann. Nucl. Ener. 35, 2259 (2008).

[54] G. Noguere et al., Nucl. Sci. Eng. 160, 108 (2008). 